\title{
Raíces europeas en la obra de Henry James
}

por María Antonia Alvarez

La presencia de Europa en James es continua y diferente de sus antecesores. Tanto Washington Irving como Longfellow, Cooper o Hawthorne, lo hicieron en una forma típicamente americana, llena de prejuicios. James, debido a sus continuos viajes desde niño, tuvo ocasión de analizar sus experiencias y sacar sus propias conclusiones sobre el contraste de civilizaciones producido por la historia.

Desde el principio, establece una serie de oposiciones que se van a repetir a través de su obra: América suponía para James moralidad, inocencia, conciencia; Europa experiencia, tradición, y la unión de la integridad moral de New England y la condición estética proporcionada por Italia, constituían la verdadera cultura, el hombre civilizado. No obstante, el contacto con el viejo mundo no siempre ofrecía este aspecto positivo a los personajes de James, sino que en la mayoría de los casos sus protagonistas sucumben ante la corrupción o relajación que aquí encuentran.

La tensión que se percibe en toda su obra entre "presente", que identifica con América, donde toda su historia es reciente, y "pasado", Europa, cuyos viejos monumentos deteriorados por el tiempo hablan de una historia antigua, tienen su origen en la propia vida de James que, como expatriado, siente por un lado el compromiso con el pensamiento y la forma de ser americanos, y por otro la atracción creciente de la cultura europea.

Al examinar detenidamente sus referencias a la cultura y arte europeos vemos que progresivamente se van haciendo más profundas: en sus primeros apuntes de viajes se concentra en la arquitectura, la pintura; después se interesa principalmente por las costumbres, el ambiente; hacia el final de su carrera artística, sus cartas, libros de notas y novelas mayores, reflejan su visión del derrumbamiento de la civilización occidental, la destrucción de los valores que caracterizan al hombre civilizado. Y por último, llega a conseguir una "fusión social" entre ambos continentes, como resultado de las relaciones cada vez más estrechas de estas dos mentalidades opuestas.

Las obras que mejor representan esta influencia europea sobre James pueden agruparse en dos grandes temas:

1. "Europa y el artista americano". Estas obras ofrecen una amplia visión del pensamiento de James. Creía que el artista americano no podía alcanzar su plenitud en su país, donde no había ni escuelas de artes, ni grandes artistas, ni un ambiente propicio para el creador. El escritor no encontraba ni ruinas del pasado, ni misterio, ni grandes acontecimientos para inspirarse, sino solamente la prosperidad prosaica de una nación en pleno desarrollo.

En sus viajes a Italia, James había observado de cerca una serie de "casos" de artistas - Ćl mismo era uno de ellos-, y todo esto después lo fue incorporando en sus obras. 
En The Madonna of the Future, nos presenta el artista impotente, que pasa su vida en una charla incesante describiendo la Madonna que va a pintar, pero cuando muere no deja más que un lienzo en blanco, ya agrietado y descolorido por el tiempo. Otros dos artistas de la colonia americana son el pintor que únicamente posee habilidad manual, y la coleccionista de arte que carece del menor conocimiento artístico.

El tema se refiere a que Italia puede proporcionar un entorno positivo al artista, pero no los dones innatos que debe poseer para ser un gran creador.

En Roderick Hudson, presenta al artista genial, que triunfa nada más llegar a Roma, en contraste con el resto de los artistas de la colonia americana: el profesional oportunista, el de aspiraciones modestas, la pintora amatcur; son hábiles en su profesión, pero les falta inspiración, son la medianía.

Esta es su primera novela importante, precisamente porque en ella se anticipa todo el mundo literario de James: la relación de Roderick con Mallet, es similar a la de Chad con Strether en The Ambassadors. Christine Light es antecedente de Madame Merle en The Portrait of a Lady, Kate Croy en The Wings of the Dove, y Charlotte en The Golden Bowl.

La descripción que nos ofrece de Roma es una de las cosas más brillantes: la antigua ciudad imperial y papal proporciona a Hudson el entorno que necesita -obras de arte de grandes maestros como Miguel Angel, un estudio en un barrio pintoresco, mármol de Carrara- en contraste con las limitaciones de su pequeña ciudad de Massachusett.

El mayor contraste se produce en la pareja central: Roderick no sabe vencer los peligros que encuentra en una sociedad con experiencia de siglos y sucumbe. En cambio su prometida Mary Garland, la joven americana, sabe aunar el sentido estético que le brinda Italia con su integridad moral, lo que la eleva al ideal de James: el espíritu culto y civilizado a que aspiran todos sus personajes.

"The Aspern Papers" son las cartas amorosas que un famoso poeta americano escribió en Venecia a su musa, y en este poema James se evoca a sí mismo como era, o mejor, como le hubiera gustado ser.

Este es uno de los mejores ejemplos de novela corta de toda la literatura, ya que la escribió en la cúspide de su vida artística, 1888. Lo que se denomina su "época mayor" es más elaborada o preciosista, y ésta es principalmente concisa y sutil.

La oposición "presente"-"pasado" domina toda la obra: la amante anciana rememora su antigua pasión a través de las cartas que conserva como su mayor tesoro; el diletante americano quiere rastrear las huellas del pasado en la vida del poeta que tanto admira y llega a extremos insospechados por conseguir esas cartas, pero no es capaz de dar el paso final; ante la idea de tener que aceptar al mismo tiempo a la vulgar poseedora, retrocede a su mundo moral, lo que es muy característico en los héroes de James, entrocado con el famoso sentido Puritano del deber.

Lo más delicado de esta obra maestra es el monólogo interior del narradorprotagonista, después de huir derrotado por no haber podido conseguir su propósito. Según le va llevando el gondolero a través de los canales venecianos la visión de la ciudad decadente se funde con la profundidad de sus sentimientos ante su desastre personal, en la más brillante demostración del stream-of consciousness que caracterizará posteriormente a Virginia Woolf, Joyce y Faulkner.

2. "Europa y la joven americana" es el gran tema de James. Esta joven americana 
independiente, segura de sí misma, se convierte en el símbolo de las cualidades positivas de América: moral, espontaneidad, delicadeza. El antecedente es Minny Temple, su prima y quizá único y verdadero amor de James, que murió en Europa a los 25 años, y a la que dedicó en sus cartas adjetivos como "espíritu divino e inquieto", "una experiencia de la naturaleza", "heredera de todos los tiempos", etc.

En estas obras James analiza el conflicto que se produce al no querer renunciar la joven a su herencia americana, como han hecho los expatriados que encuentra en Italia. Henry James es el descubridor de la muchacha americana como tipo y fenómeno social, muy superior al que presentaron sus antecesores, principalmente Hawthorne.

"Daisy Miller" durante muchos años, caracterizó la figura de la joven americana moderna, encantadora, valiente, que sucumbe en Italia por la incomprensión de sus compatriotas expatriados, y contra los cuales su inocencia no sabe cómo luchar.

Isabel Archer, en The Portrait of a Lady, es su más brillante representación de la "American girl". Está deseosa de saber, de vivir, de correr tras los más altos ideales, pero sucumbe ante lo vulgar y corrupto de la sociedad europea. Al final, después del sufrimiento, se transforma en la "American lady" que afronta su destino, llegando a realizarse totalmente.

Isabel contrasta con el otro personaje central, el cínico y presuntuoso Gilbert Osmond, un americano expatriado en Italia. Pocos villanos psicológicos han sido nunca mejor dibujados. A su vez Osmond contrasta con el vigoroso hombre de negocios americano, espontáneo, natural, sencillo, insensible al arte, pretendiente de Isabel desde el principio de la obra, y a quien ella rechaza una y otra vez, rechazando en su persona a América, por creer que la van a privar de su libertad.

Florencia y Roma están retratadas con toda minuciosidad: sus monumentos, sus museos, la maravillosa "campagna" italiana. Las diversas mansiones en que se desarrolla la acción, tienen carácter simbólico y contrastan entre sí: la villa florentina de Osmond tiene la fachada "como una máscara", que refleja la dudosa personalidad del duefio; el palacio romano, cerrado y oscuro, representa una cárcel para Isabel después del matrimonio. Ambas contrastan con Gardencourt, en la que James hace un emocionado tributo a la "English country house", por su enorme significación cultural y de refinamiento. Es en ella donde Isabel acarició sus sueños de ser libre. Los lugares artísticos emanan un influjo como de encantamiento sobre el visitante. Así Osmond, el personaje diabólico, declara su pasión amorosa a Isabel dentro de la Basílica de San Pedro. Isabel está absorta ante el cúmulo de objetos artísticos del pasado, que no le permite ver con claridad su presente, ni la trampa que la tienden para privarla de lo que más ansía: su libertad.

Cuando descubre el engafio, vuelve a Roma en nombre de algo sagrado y precioso: su propia identidad.

En The Wings of the Dove, James presenta la más espiritual de sus heroínas, Milly Theale. La obra está totalmente enmarcada en Venecia. Como ciudad en la que se mezclan las culturas oriental y occidental, Venecia es el escenario perfecto para la encarnación de Milly, la "heredera de todos los tiempos", y como ciudad decadente y muerta, es el marco adecuado para su desaparición. La peculiar geografía cerrada de Venecia, donde incluso la Plaza de San Marcos es como "a great drawing-room", la convierte en la mejor imagen del estado mental de claustrofobia del drama, con Milly 
encerrada y silenciosa en su palacio hasta su muerte. Venecia se adapta tanto a la acción, que incluso cambia cuando aparece la tragedia: de verano luminoso, pasa a tormenta, lluvia, oscuridad, cuando Lord Mark -que irónicamente lleva el nombre del Santo Patrono de la ciudad-, le confiesa la sucia intriga tramada sobre ella.

En esta novela James dramatiza la desintegración de la civilización occidental, y lo hace a través de la idea de Milly, que considera que el arte es irrelevante para la vida moderna.

En The Golden Bowl, la "American girl" sufre una transformación: en vez de sucumbir como sus antecesoras, sin abandonar su moral aunque si su inocencia, se convierte en la mujer inteligente y apasionada.

Al contrario de las demás obras, ésta no se desarrolla en Italia. Lo que le interesa aquí a James son las costumbres tradicionales de la aristocracia romana, para contrastarlas con las de América.

La figura del Príncipe Amerigo es la expresión más clara de la simpatía que durante toda su vida sintió James por la civilización latina, y supone uno de sus grandes logros: es sensual, joven, viril, incapaz de hipocresía, católico de hecho aunque de sensibilidad pagana: su esteticismo es una forma de su materialismo. Se transforma de forma tan vigorosa su carácter a través de la obra, que aquí el contraste se produce entre el primero y el segundo Amerigo.

Las dos figuras femeninas son opuestas: Maggie, la muchacha americana que encarna todos los valores positivos, y Charlotte, la expatriada, aunque James la trata mejor que a otros personajes.

Pero el contraste más importante de la novela está en las dos orientaciones de vida, las dos actitudes básicas que controlan las respuestas y la conducta de los individuos: el viejo y el nuevo mundo, la Italia clásica y la América moderna. Tanto Maggie como Amerigo están vistos históricamente, son la representación más acabada de sus respectivas civilizaciones.

Por única vez en Henry James todo se resuelve: el matrimonio se realiza, lo que había venido resultando imposible a través de su obra entre representantes de las dos civilizaciones; América y Europa, antes irreconciliables, llegan a una "fusión social", como resultado de las relaciones que se han ido estrechando entre ambas mentalidades opuestas.

La ficción de Henry James cubre el curso total de la historia de la novela durante casi un siglo y puede considerarse el maestro del realismo psicológico. Durante toda su carrera artística, el interés constante de James fue descubrir los medios más efectivos de crear una ilusión de la realidad de la vida y el llamado "resurgimiento" de Henry James ha sido en realidad el descubrimiento de James como una figura literaria mundial, un puente entre el movimiento romántico y todo lo que es moderno en el arte literario del siglo XX.

El secreto de que perdure su fama es muy simple: trató exclusivamente de las tensiones que produce la civilización, escribió del hombre y de la mujer en su lucha por controlar emociones y pasiones dentro de la moral y las costumbres de la sociedad, comprendió el motivo y el comportamiento del ser humano; buscó la belleza en vez de la fealdad, la amabilidad en vez de la crueldad y la paz en vez de la violencia. 